\title{
Vaccination in Adults with Chronic Lung Disease - Revisiting 2019 Immunization Guidelines
}

\author{
Rohit Vadala, Isabella Princess ${ }^{1}$, Pratap Upadhya ${ }^{2}$ \\ Metro Centre for Respiratory Diseases, Metro Multispeciality Hospital, Noida, Uttar Pradesh, ${ }^{1}$ Department of Microbiology, Apollo Speciality Hospitals, Chennai, \\ Tamil Nadu, ${ }^{2}$ Department of Pulmonary Medicine, Jawaharlal Institute of Postgraduate Medical Education and Research, Puducherry, India
}

\section{Abstract}

Effective immunization programs have always resulted in successful eradication of targeted infectious diseases. Apart from childhood immunization, adult immunization is required for two major reasons: 1. failure of primary immunization, 2. to boost waning effect of childhood vaccines. Adult immunization gained its importance in the recent years with detailed recommendations laid down by the World Health Organization (WHO) and the Centers for Disease Control and Prevention (CDC). In most countries, adult vaccination guidelines fall back on the WHO and CDC adult immunization schedules. With evolving number of chronic lung disease patients, it is mandatory to educate and encourage patients on available options for vaccination. A successful immunoprophylaxis given to high-risk group individuals will definitely improve their quality of life.

Keywords: Adult vaccination, chronic lung disease, immunization, vaccine

\section{INTRODUCTION}

An effective immunization in high-risk individuals plays a cost-effective beneficial role in reducing morbidity and mortality. ${ }^{[1,2]}$ Most vaccines target viral infections which do not have a definitive treatment option and also infections with a high mortality rate. ${ }^{[1,2]}$ Another possible reason for recommending the use of a vaccine is the rise in the incidence of newer or re-emerging infections. Immunosuppressed individuals have a greater risk in acquiring infections compared to normal individuals due to a major compromise in cell-mediated immunity. Chronic lung disease being one among the most common chronic illnesses is an absolute indication for vaccination in adults. Detailed guidelines for adult vaccination have been recommended by the World Health Organization (WHO) and Centers for Disease Control and Prevention (CDC) which were updated recently in 2019. ${ }^{[1,2]}$ Among these schedules, $\mathrm{CDC}$ gives detailed recommendations for adults with chronic underlying conditions. Physicians in India follow adult vaccination guidelines recommended by the CDC or the WHO since Indian guidelines are limited and not updated. In this article, we intend to review adult vaccines recommended specifically in patients with underlying lung diseases. In a country like India where tuberculosis is

\begin{tabular}{|l|l|}
\hline \multicolumn{2}{|c|}{ Access this article online } \\
\hline Quick Response Code: & Website: \\
\hline & www.ijrc.in \\
\cline { 2 - 2 } & \\
\hline
\end{tabular}

a forerunner and other chronic lung diseases are prevalent, vaccination is rather mandatory than optional. We, therefore, review the latest recommendation on immunization of adults with chronic lung disease.

\section{Immunization in patients with chronic lung disease}

An expert group of physicians in 2009 came up with recommendations for various vaccines for adults in India. The updated version of these recommendations is however not available. In order to clarify the recommendation for immunization of adults with chronic lung disease, the updated CDC guidelines have been consulted [Table 1].

Vaccine recommendations for all adults have been broadly grouped into various categories. However, there are no vaccines which are contraindicated in patients with chronic lung disease. Thus, vaccine recommendations in this group of

Address for correspondence: Dr. Pratap Upadhya, Department of Pulmonary Medicine, Jawaharlal Institute of Postgraduate Medical Education and Research, Puducherry, India. E-mail: drpratpu@gmail.com

This is an open access journal, and articles are distributed under the terms of the Creative Commons Attribution-NonCommercial-ShareAlike 4.0 License, which allows others to remix, tweak, and build upon the work non-commercially, as long as appropriate credit is given and the new creations are licensed under the identical terms.

For reprints contact: WKHLRPMedknow_reprints@wolterskluwer.com

How to cite this article: Vadala R, Princess I, Upadhya P. Vaccination in adults with chronic lung disease - Revisiting 2019 immunization guidelines. Indian J Respir Care 2021;10:19-23.

Received: $22-04-2020 \quad$ Revised: $15-09-2020$ Accepted: 27-09-2020 Published: 31-01-2021 
Vadala, et al.: Vaccines in chronic lung disease

patients fall in either one of the above mentioned categories in Table 1. The reason for vaccine recommendations in chronically ill patients is their susceptibility to infection and the benefits of vaccination outweighing the risk of acquiring infection. ${ }^{[3]}$

\section{Influenza vaccination}

Influenza vaccines are available as inactivated vaccine preparations as well as live influenza vaccines. The inactivated influenza vaccine is safer for use in patients with immunocompromising conditions. A single dose of influenza vaccine is recommended annually since the strains causing infection undergo frequent mutation. ${ }^{[4]}$ Live influenza vaccines may be used with precaution if the benefit outweighs the risk of adverse reaction.

Precautions should be taken while administering inactivated influenza vaccine in patients with risk of adverse reaction such as severe urticaria due to egg allergy. In such cases, medical assistance and supervision by a health-care provider is mandatory while vaccinating such individuals. The influenza vaccine is safe for use in all patients over 5 years of age. Trivalent and quadrivalent influenza strains are available as influenza vaccines. India belongs to the Southern Hemisphere influenza vaccination zone. The most recent vaccine strain licensed by the WHO is for the 2019-2020 influenza season containing all prevalent strains which have caused epidemics in the recent past..$^{[5]}$

Flu vaccines provide better protection against influenza $\mathrm{B}(54 \%)$ or influenza A (H1N1) viruses (61\%) than against influenza A (H3N2) viruses (33\%). ${ }^{[6]}$ Efficacy studies among high-risk groups show reduced death rate, intensive care unit (ICU) admissions by $79 \%$ in a study from England, length of stay in the ICU, and much benefit in all age groups including patients with diabetes, heart disease, chronic lung diseases, etc. ${ }^{[6,7]}$

\section{Pneumococcal vaccination}

Pneumococcal infections can be life-threatening and devastating, but at the same time, preventable with available conjugate (PCV 13) and polyvalent (pneumococcal polysaccharide vaccine 23 [PPSV23]) pneumococcal vaccines. These vaccines can be effectively used in immunocompromised individuals as well as children due to the fact that they are not live vaccines. The recommended pneumococcal vaccine for adults with chronic lung disease from 19 to 64 years of age is a single dose of PPSV23. Since adults with chronic lung diseases are prone to pneumococcal infection with drug-resistant strains, vaccination against the same is desirable. ${ }^{[8]} \mathrm{A}$ dosage of $0.5 \mathrm{ml}$ is administered by intramuscular or subcutaneous route. There exist small variations in vaccine specifications of the same as listed in Table 2.

Once a schedule is initiated, product switching between conjugate and polysaccharide vaccines is not recommended. Pneumococcal conjugate vaccine can be administered along with other vaccines since there is no significant alteration in the immunogenicity of the vaccine. ${ }^{[9]}$

\begin{tabular}{|c|c|}
\hline Categories & Recommended vaccines \\
\hline $\begin{array}{l}\text { Recommended for adults who meet } \\
\text { age requirement, lack documentation } \\
\text { of vaccination, or lack evidence of past } \\
\text { infection }\end{array}$ & $\begin{array}{l}\text { IIV or RIV } \\
\text { PPSV } 23 \\
\text { Tdap or Td } \\
\text { MMR } \\
\text { VAR } \\
\text { RZV } \\
\text { HPV - male and female }\end{array}$ \\
\hline $\begin{array}{l}\text { Recommended for adults with an } \\
\text { additional risk factor or another indication }\end{array}$ & $\begin{array}{l}\text { Hib } \\
\text { MenACWY and MenB } \\
\text { PCV13 } \\
\text { Hep A } \\
\text { Hep B }\end{array}$ \\
\hline $\begin{array}{l}\text { Precaution - vaccine might be indicated } \\
\text { if benefit of protection outweighs risk of } \\
\text { adverse reaction }\end{array}$ & LAIV \\
\hline \multicolumn{2}{|c|}{$\begin{array}{l}\text { IIV: Influenza inactivated, RIV: Recombinant influenza vaccine, } \\
\text { PPSV23: Pneumococcal polysaccharide vaccine, MMR: Measles, Mumps, } \\
\text { Rubella, VAR: Varicella, RZV: Zoster recombinant vaccine, HPV: Human } \\
\text { papillomavirus, MenACWY: Meningococcal A, C, W, Y, Hib: Haemophilus } \\
\text { influenzae type b, MenB: Meningococcal B, PCV13: Pneumococcal conjugate } \\
\text { vaccine, Hep A: Hepatitis A, Hep B: Hepatitis B, } \\
\text { LAIV: Live-attenuated influenza vaccine, Tdap or Td: Tetanus, Diphtheria, } \\
\text { Pertussis }\end{array}$} \\
\hline
\end{tabular}

Table 2: Recommendations for pneumococcal vaccines in chronic lung disease

\begin{tabular}{ll}
\hline Patient type & $\begin{array}{l}\text { Pneumococcal vaccine } \\
\text { recommendation }\end{array}$ \\
\hline $\begin{array}{l}\text { Patients aged between 19 and 64 } \\
\text { years }\end{array}$ & Single dose of PPSV23 \\
$\begin{array}{l}\text { Patients aged 19-64 years with an } \\
\text { immunocompromising condition (e.g., }\end{array}$ & 1 dose PCV13 \\
$\begin{array}{l}\text { HIV infection, solid organ transplant, } \\
\text { chronic renal disease, malignancy, B }\end{array}$ & $\begin{array}{l}\text { 1 dose PPSV23 after } 8 \text { weeks from previous PPSV23 } \\
\text { and T lymphocyte deficiency) }\end{array}$ \\
$\begin{array}{l}\text { Patients above 65 years with an } \\
\text { immunocompromising condition }\end{array}$ & $\begin{array}{l}1 \text { dose PPSV23 5 years after } \\
\text { most recent PPSV23 (note: only }\end{array}$ \\
& $\begin{array}{l}1 \text { dose PPSV23 recommended at } \\
\text { age 65 years or older) }\end{array}$ \\
\hline
\end{tabular}

PPSV23: Pneumococcal polysaccharide vaccine

\section{Tetanus, diphtheria, and pertussis vaccination}

Recently, the WHO has confirmed the shift of the tetanus toxoid vaccine to a combination vaccine containing two antigens (diphtheria and tetanus), namely DT or Td. The current vaccine recommended for coverage of these three infections is a single dose of Tdap, followed by a Td booster once in every 10 years. Apart from these, a DTaP vaccine formulation is also available against diphtheria, tetanus, and pertussis. ${ }^{[10]}$ The pertussis component can be present as acellular (DTaP) or whole cell (DTwP) form, both being safe and efficacious. The DTaP or DTwP vaccines can also be administered in combination with other vaccine antigens. Diphtheria-containing vaccine formulations are administered as $0.5 \mathrm{ml}$ dose intramuscularly. ${ }^{[11]}$ 
Vadala, et al: Vaccines in chronic lung disease

\section{Measles, mumps, and rubella vaccination}

MMR is a live attenuated vaccine which should be given as two doses in unimmunized individuals. In adults with previous history of immunization, one dose of MMR is sufficient. In unimmunized individuals, the two doses should be administered 4 weeks apart. Two doses of MMR vaccine is indicated in HIV-infected individuals with CD4 count $\geq 200$ cells $/ \mu \mathrm{L}$ for at least 6 months and no evidence of immunity to measles, mumps, or rubella. MMR is contraindicated in otherwise severely immunocompromised patients as it is a live-attenuated vaccine. ${ }^{[2]}$ Immune response after vaccination can be monitored by estimating the levels of IgG against these antigens. Adverse reactions are very rare with MMR vaccine. The controversial relationship between MMR vaccine and autism has been ruled out by various scientific studies. ${ }^{[12]}$ The dose of MMR for any age is $0.5 \mathrm{ml}$ subcutaneously, preferably into the outer aspect of the upper arm. ${ }^{[13]}$

\section{Varicella vaccine}

The current WHO recommendation for this vaccine in patients with chronic lung disease is two doses at an interval of 4-8 weeks. The dose of vaccine is $0.5 \mathrm{ml}$ given subcutaneously. ${ }^{[14]}$ This vaccine is administered in individuals who lack an evidence of varicella antibodies in serum/lacking evidence of varicella immunity. Since it is a live vaccine, varicella vaccine is contraindicated in severe immunocompromising conditions as well as in pregnancy. It can safely be administered along with other inactivated vaccines. However, while co-administering another live vaccine such as MMR, a minimum interval of 28 days is recommended between doses. ${ }^{[1]}$

\section{Zoster recombinant vaccine}

Zoster vaccine is recommended for use in all patients over the age of 60 years. It can be safely used in individuals with chronic medical conditions and in patients with a previous history of zoster. A single dose is administered subcutaneously at a dosage of $0.65 \mathrm{ml}$ given irrespective of the past history of varicella. However, this vaccine cannot be used to treat acute herpes zoster, as preventive measure for the development of postherpetic neuralgia or to treat an ongoing postherpetic neuralgia. ${ }^{[3]}$ It is commercially available in the name of "Zostavax."

\section{Human papillomavirus vaccine}

Three doses of HPV vaccine is recommended for adolescents $\geq 15$ years of age and adults through 26 years of age at a dose of $0.5 \mathrm{ml}$ intramuscularly. A three-dose schedule (0.1-2.6 months) is ideal with either an available bivalent or tetravalent HPV vaccine. ${ }^{[15]}$ The bivalent vaccine contains virus-like particles of genotypes 16 and 18; the quadrivalent vaccine contains genotypes 6 and 11 in addition to those contained in the bivalent vaccine. ${ }^{[16]}$ Studies have shown a vaccine efficacy of over $90 \%$ in individuals who received all three doses of the vaccine. Nonavalent HPV vaccine containing nine genotypes of HPV is now available. The nonavalent vaccine is administered as a two-dose schedule (if the first dose is given before 14 years) with an interval of 6-12 months between the two doses. However, older and immunocompromised individuals should continue to receive the three-dose schedule at 0,2 , and 6 months. ${ }^{[17]}$

\section{Vaccines recommended in adults with an additional risk factor or any other condition Haemophilus influenzae type $b$ vaccine}

A single dose of Haemophilus influenzae type b (Hib) vaccine is recommended in adults with chronic lung disease. Available as capsular polysaccharide or conjugate vaccines, they are not routinely indicated in normal adults with no underlying medical condition. ${ }^{[18]}$

In people who undergo splenectomy, Hib vaccine should be administered 14 or more days before splenectomy, if possible. Hib vaccines are not recommended in individuals infected with HIV as the preponderance to Hib infection in these groups of patients is negligible. ${ }^{[18]}$ A nontypeable Haemophilus influenzae (NTHi) oral vaccine in preventing repeated infections among patients with COPD and chronic bronchitis was evaluated. On review of various studies, it was concluded that there was no significant reduction in the number of exacerbations of COPD in individuals receiving oral NTHi vaccine. ${ }^{[19]}$

\section{Meningococcal vaccination}

Meningococcal vaccines are recommended only in individuals under any one of the following category: ${ }^{[15,20]}$

- Adults with asplenia, complement deficiencies, and HIV

- Military recruits and $11^{\text {st }}$ year college students who live in residential housing

- Persons who travel to or live in countries where the disease is hyperendemic or epidemic meningococcal disease

- $\quad$ Travel to Mecca

- Close contacts to infected individuals and health-care workers during outbreaks

- Laboratory personnel handling cultures of Neisseria meningitides.

In adults, a single dose of polysaccharide or conjugate vaccine is recommended at a dosage of $0.5 \mathrm{ml}$ administered intramuscularly. Currently available meningococcal vaccines are either bivalent (Neisseria meningitidis serogroups A and C) or quadrivalent (Neisseria meningitidis serogroups A, C, Y, and $\mathrm{W}-135) .{ }^{[21]}$ Men B vaccine was first licensed for use in 2014 and is given as 2-3 doses of $0.5 \mathrm{ml}$ each intramuscularly. Men $B$ vaccine is not routinely used in patients with chronic lung disease. The choice of administering this vaccine is based on clinician's judgment if the patient has another coexisting risk factor. Meningococcal vaccines are absolutely indicated in patients undergoing splenectomy since Meningococci are capsulated organisms. ${ }^{[2,4]}$

\section{Hepatitis vaccines}

Hepatitis A vaccine is recommended in patients with an added condition such as chronic liver disease, infected with other 
Vadala, et al.: Vaccines in chronic lung disease

\begin{tabular}{|c|c|c|c|}
\hline Name of vaccine & Type of vaccine & Dose and route & Schedule \\
\hline Influenza vaccine & Inactivated & $0.5 \mathrm{ml}$, intramuscular & Single dose, yearly \\
\hline PPSV23 & Purified capsular polysaccharide & $\begin{array}{l}0.5 \mathrm{ml} \text {, intramuscular or } \\
\text { subcutaneous }\end{array}$ & Single dose \\
\hline Tdap or Td & Toxoid and inactivated & $0.5 \mathrm{ml}$, intramuscular & 1 Tdap, Td booster once in every 10 years \\
\hline MMR & Live attenuated & $0.5 \mathrm{ml}$, subcutaneous & 2 doses, 4 weeks apart \\
\hline VAR & Live attenuated & $0.5 \mathrm{ml}$, subcutaneous & 2 doses, $4-8$ weeks apart \\
\hline $\mathrm{RZV}$ & Live attenuated & $0.65 \mathrm{ml}$, subcutaneous & Single dose \\
\hline HPV & Inactivated & $0.5 \mathrm{ml}$, intramuscular & $0,1-2,6$ months \\
\hline Hib & Capsular polysaccharide or conjugate vaccines & $0.5 \mathrm{ml}$, intramuscular & Single dose \\
\hline MenB & Capsular polysaccharide or conjugate vaccines & $\begin{array}{l}\text { Men ACWY and Men B - } 0.5 \text { ml, } \\
\text { intramuscular }\end{array}$ & Men ACWY: Single dose; Men B: $2-3$ doses \\
\hline Hep A & Inactivated single antigen & $0.5 \mathrm{ml}$, intramuscular & 2 doses, $6-12$ months apart \\
\hline Hep B & Recombinant DNA & $20 \mu 1$, intramuscular & $0,1,6$ months \\
\hline LAIV & Live attenuated & $0.2 \mathrm{ml}$, intranasal & Single dose \\
\hline
\end{tabular}

hepatitis viruses, food handlers, awaiting/undergone liver transplant, men who have sex with men, injection drug users, patients receiving platelet concentrates, and end-stage renal disease. ${ }^{[2]}$ Two schedules namely, a single antigen two-dose schedule or a combined HAV-HBV vaccine three-dose schedule may be followed. The single HAV antigen vaccine is given as two doses spaced 6-12 months apart. ${ }^{[2,15]}$

Hepatitis B vaccine is available as a recombinant DNA vaccine given intramuscularly at a dose of $20 \mu \mathrm{l}$ at 0,1 , and 6 months. A booster after 5 years is given only for immunosuppressed individuals; healthy and otherwise immunocompetent adults do not require the booster dose. ${ }^{[23]}$ The recommendation for adult patients receiving hemodialysis or with other immunocompromised conditions is 1 dose of $40 \mu \mathrm{g} / \mathrm{mL}$ administered on a 3 -dose schedule or 2 doses of $20 \mu \mathrm{g} / \mathrm{mL}$ administered simultaneously at $0,1,2$, and 6 months. ${ }^{[15]} \mathrm{A}$ protective anti-HBs antibody titer of $\geq 10 \mathrm{mIU} / \mathrm{ml}$ should be ensured after completion of all doses of vaccination. ${ }^{[24]}$

\section{The way forward}

Adult immunization is a neglected entity in India due to ignorance as well as public unawareness regarding the benefits of vaccination. With recent changing trends in infectious diseases, emergence of viruses, frequent outbreaks, and epidemics, it is important to target vaccine-preventable infectious diseases. This will not only improve the quality of life in chronically ill patients but also help in the "cocooning" effect which protects the immediate contacts and family members of vaccinated individuals, e.g., pertussis infection among children. ${ }^{[25]}$ Cocooning is a strategy deployed to indirectly protect infants and other individuals who cannot be vaccinated by vaccinating their parents and other close contacts. This strategy protects the vaccinated adult as well as his/her close contacts. ${ }^{[26]}$ Considering all the benefits of vaccinating adults with chronic lung disease which is highly prevalent in India, the above discussed vaccines should be recommended and given to these individuals. Table 3 summarizes the vaccines recommended for use in chronic lung disease.

\section{Conclusion}

We have portrayed the importance of immunoprophylaxis in patients with chronic lung disease. Indian guidelines are not very elaborate on recommendations among this group. In order to clarify the same, a thorough review of the CDC and WHO adult vaccination guidelines of 2019 has been done. Chronic lung disease being the forerunner of chronic illnesses in India, clinicians can apply these guidelines while treating patients with chronic lung disease.

\section{Financial support and sponsorship}

Nil.

\section{Conflicts of interest}

There are no conflicts of interest.

\section{REFERENCES}

1. World Health Organization. Recommended Routine Immunization. World Health Organization; 2019. Accessed from: http://www.who. int/immunization/documents/positionpapers/. [Last accessed on 2019 Jul 24].

2. Centers for Disease Control and Prevention. Recommended Adult Immunization Schedule, United States; 2019.

3. National Center for Immunization and Respiratory Diseases. General recommendations on immunization Recommendations of the Advisory Committee on Immunization Practices (ACIP). MMWR Recomm Rep 2011;60:1-64

4. Adult immunization. CD Alert. Monthly Newsletter of National Centre for Disease Control, Directorate General of Health Services, Government of India; 2011.

5. World Health Organization. Recommended Composition of Influenza Virus Vaccines for Use in the 2019-2020 Northern Hemisphere Influenza Season; 21 February, 2019. p. 1-9.

6. Belongia EA, Simpson MD, King JP, Sundaram ME, Kelley NS, Osterholm MT, et al. Variable Influenza Vaccine Effectiveness by Subtype: A Systematic Review and Meta-Analysis of Test-negative Design Studies. Available from: https://www.thelancet.com/pdfs/ 
journals/laninf/PIIS1473-3099 (16) 00129-8.pdf. [Last accessed on 2020 Sep 15].

7. Vaccine Effectiveness: How Well Do the Flu Vaccines Work? Accessed from: https://www.cdc.gov/flu/vaccines-work/vaccineeffect. htm\#present-data. [Last accessed on 2020 Sep 15].

8. Pneumococcal Conjugate Vaccines in Infants and Children Under 5 Years of Age: Vol. 94. WHO Position Paper; February, 2019. p. 85-104. Available from: http://www.who.int/wer. [Last accessed on 2020 Sep 15].

9. Recommendations to Assure the Quality, Safety and Efficacy of Pneumococcal Conjugate Vaccines (WHO Technical Report Series, No. 977, Annex 3). Genève: Organisation Mondiale de la Santé; 2013.

10. Diphtheria Vaccination. National Center for Immunization and Respiratory Diseases; 2018. Accessed from: https:/www.cdc.gov/ vaccines/vpd/diphtheria/index.html. [Last accessed on 2019 Sep 30].

11. Diphtheria Vaccine: WHO Position Paper. Vol. 92. Weekly Epidemiological Record; 2017. p. 417-36.

12. Understanding MMR Vaccine Safety; 2013. Accessed from: https:// www.cdc.gov/vaccines/hcp/patient-ed/conversations/downloadds/ vacsafe-mmr-color-office.pdf. [Last accessed on 2019 Sep 30].

13. M-M-R II (Measles, Mumps and Rubella virus vaccine live). Available from: www.merck.com/product/patent/home.html. [Last accessed on 2019 Sep 30].

14. Chickenpox (Varicella) Vaccine Administration; 2019. Accessed from: https://www.cdc.gov/vaccines/vpd/varicella/hcp/administeringvaccine.html. [Last accessed on 2019 Sep 30].

15. Ramasubramanian V. Adult Vaccination in India. Ch. 6. Available from: http://www.apiindia.org/pdf/progress_in_medicine_2017/mu_06. pdf. [Last accessed on 2019 Jul 24].

16. Cutts FT, Franceschi S, Goldie S, Castellsague X, de Sanjose S, Garnett G, et al. Human papillomavirus and HPV vaccines: A review. Bull World Health Organ 2007;85:719-26.
17. Brotherton JM. Human papillomavirus vaccination update: Nonavalent vaccine and the two-dose schedule. Aust J Gen Pract 2018;47:417-21.

18. Prevention and Control of Haemophilus influenzae Type b Disease Recommendations of the Advisory Committee on Immunization Practices (ACIP). Morbidity and Mortality Weekly Report CDC; 2014.

19. Teo E, Lockhart K, Purchuri SN, Pushparajah J, Cripps AW, van Driel ML. Haemophilus influenzae oral vaccination for preventing acute exacerbations of chronic bronchitis and chronic obstructive pulmonary disease. Cochrane Database Syst Rev. 2017 Jun 19;6(6):CD010010. doi: 10.1002/14651858.CD010010.pub3. PMID: 28626902; PMCID: PMC6481520.

20. International Travel and Health: Meningococcal Disease. World Health Organization. Available from: https://www.who.int/ith/vaccines/ meningococcal/en/. [Last accessed on 2019 Oct 01].

21. Rosenstein NE, Perkins BA, Stephens DS, Popovic T, Hughes JM. Meningococcal disease. N Engl J Med 2001;344:1378-88.

22. Danzinger-Isakov L, Kumar D, AST Infectious Diseases Community of Practice. Guidelines for vaccination of solid organ transplant candidates and recipients. Am J Transplant 2009;9 Suppl 4:S258-62.

23. Guidelines for Vaccinating Dialysis Patients and Patients with Chronic Kidney Disease. Summarized from Recommendations of the Advisory Committee on Immunization Practices (ACIP); 2012.

24. Schroth RJ, Hitchon CA, Uhanova J, Noreddin A, Taback SP, Moffatt ME, et al. Hepatitis B vaccination for patients with chronic renal failure. Cochrane Database Syst Rev 2004;3:CD003775.

25. Rowe SL, Tay EL, Franklin LJ, Stephens N, Ware RS, Kaczmarek MC, et al. Effectiveness of parental cocooning as a vaccination strategy to prevent pertussis infection in infants: A case-control study. Vaccine 2018;36:2012-9.

26. Nitsch-Osuch A. Cocoon Strategy of Vaccinations: Benefits and Limitations; 2017. p. 3-22. 